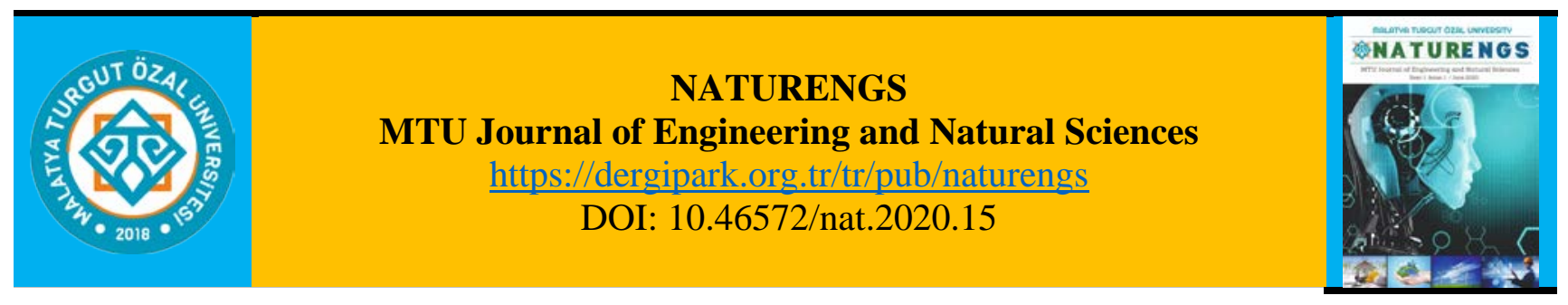

\title{
Correlations Between SPT, PMT and MASW on Quaternary Alluvial - Fluvial Sediments in Battalgazi, Malatya, Turkey
}

\author{
Çiğdem CEYLAN ${ }^{1 *}$, Mehmet ÖNAL ${ }^{2}$ \\ ${ }^{1}$ Department of Civil Engineering, Faculty of Engineering and Natural Sciences, Malatya Turgut Özal \\ University, Malatya, Turkey. \\ ${ }^{2}$ Department of Mining Engineering, Faculty of Engineering, İnönü University, Malatya, Turkey.
}

(Received: 04.12.2020; Accepted: 22.12.2020)

\begin{abstract}
The field tests such as the standard penetration test (SPT), pressuremeter test (PMT), and MultiChannel Analysis of Surface Waves (MASW) give information about the stratigraphic properties, structure, underground water level, bearing capacity, and liquefaction of soil. The studies investigating the correlations between these tests are quite common. Most of the studies found in the literature have focused on sand, silty, and clay soils, while the number of studies about gravelly soils is limited. In the study area, the gravel content ranged from $0 \%$ to $47 \%$ depending on local differences. Gravel sizes reached $80 \mathrm{~mm}$ at certain locations but remained below them in most locations. In this study, it has been discussed that how correlation studies will change in heterogeneous soils. Among the correlations between the field test results, with the highest $\mathrm{R}^{2}$ value of 0.6847 , the strongest correlation was obtained between the PMT- $\mathrm{P}_{\mathrm{L}}$ value and SPT- $\mathrm{N}_{60}$ value, while, with an $\mathrm{R}^{2}$ value of 0.3906, the weakest correlation was between the PMT- $E_{m}$ value and MASW- $V_{s}$ value. The low $R^{2}$ values were attributed to the exceedingly heterogeneous structure of the soil and locally changing gravel amounts.
\end{abstract}

Keywords: Correlation, Soil tests, Alluvial-fluvial sediments.

\section{INTRODUCTION}

During an earthquake, local geology plays an important role in the control of the effect of the earthquake on the surface. Soil properties can affect the amplitude, frequency, and duration of bedrock motion when it reaches the surface [1].

In geotechnical applications, as in situ tests that do not alter the soil stress conditions, field tests are preferred over laboratory applications. These tests are prevalently used in practices such as the design of foundations and other building structures, bearing capacity, and liquefaction analysis.

Within the scope of the in situ tests, various geophysical methods are also used, among them being the Multi-Channel Analysis of Subsurface Waves (MASW), which is a series of geophysical tests done on the ground surface and used to determine the shear wave velocity 
$\left(V_{s}\right)$ profile with depth for a certain site [2]. $V_{s}$ is an important parameter revealing the stiffness of soil layers [3].

The study investigates whether there is a relationship between the SPT-N60 value (SPT N-value corrected for field procedures) obtained with the SPT, the $E_{m}$ ( Mernard deformation module) and $P_{L}$ (Limit Pressure) values obtained with the PMT, and the $V_{s}$ value obtained with the MASW test.

The study area was the Battalgazi Campus of Turgut Özal University located within the borders of Battalgazi District in the north of Malatya, Turkey (Figure 1). It has an area of about 600 decares. In the region, 15 boreholes were drilled at certain intervals and the SPT and PMT were performed in the boreholes at predetermined depths. The equations derived between the data obtained from the two tests were compared with the results found by other researchers. Again, in the same region, an MASW test was carried out at 32 points and the 15 closest MASW tests to the drilling points were used for comparison purposes. The relationship between the results and the results obtained with the SPT and PMT was examined and compared with the results found in the literature.

The maximum relation was obtained between SPT and PMT. But this relationship is quite weak. It is thought that such a result is due to the heterogeneous nature of the soil. Literature studies generally include studies on homogeneous soils and the relations obtained are quite high. However, it has been observed that as the heterogeneity of the ground increases, the relationship between SPT, PMT and MASW also gets weaker. In this study, it was investigated how the correlation studies in heterogeneous soils would yield results.

\subsection{Geological Description of the Study Area}

The study area involves the Quaternary alluvial-fluvial deposits of the Malatya basin located in the north of Battalgazi District, Malatya, Turkey. The alluvial deposits in the study area mostly comprised of treated-non-treated gravel, sand, silt, and clay-intercalated mud. The examination of the clay samples in the study area revealed that they were high-plastic clays. The pile stiffness examination showed that the pile was highly stiff. According to the seismic data, the pile had a thickness of $70 \mathrm{~m}$. The evaluation of the lithological and stratigraphic properties and sedimentary geometry of the unit revealed that the unit reflected the sedimentation in alluvial fan and flood plain settings [4]. The underground water level (GW) in the region ranged from $2.29 \mathrm{~m}$ to $6.42 \mathrm{~m}$ depending on seasonal changes. The region mostly consists of agricultural lands and agricultural and education activities are carried out together in the campus site.

\section{MATERIAL AND METHODS}

\subsection{Field Tests}

In the study area total of 15 boreholes were drilled at $250 \mathrm{~m}$ intervals. The SPT and PMT were performed for the same boreholes and correlation studies were carried out between the results obtained from both tests. Among the measurements obtained with the MASW tests, the 15 closest measurements to the drilling points were used in the comparisons. 


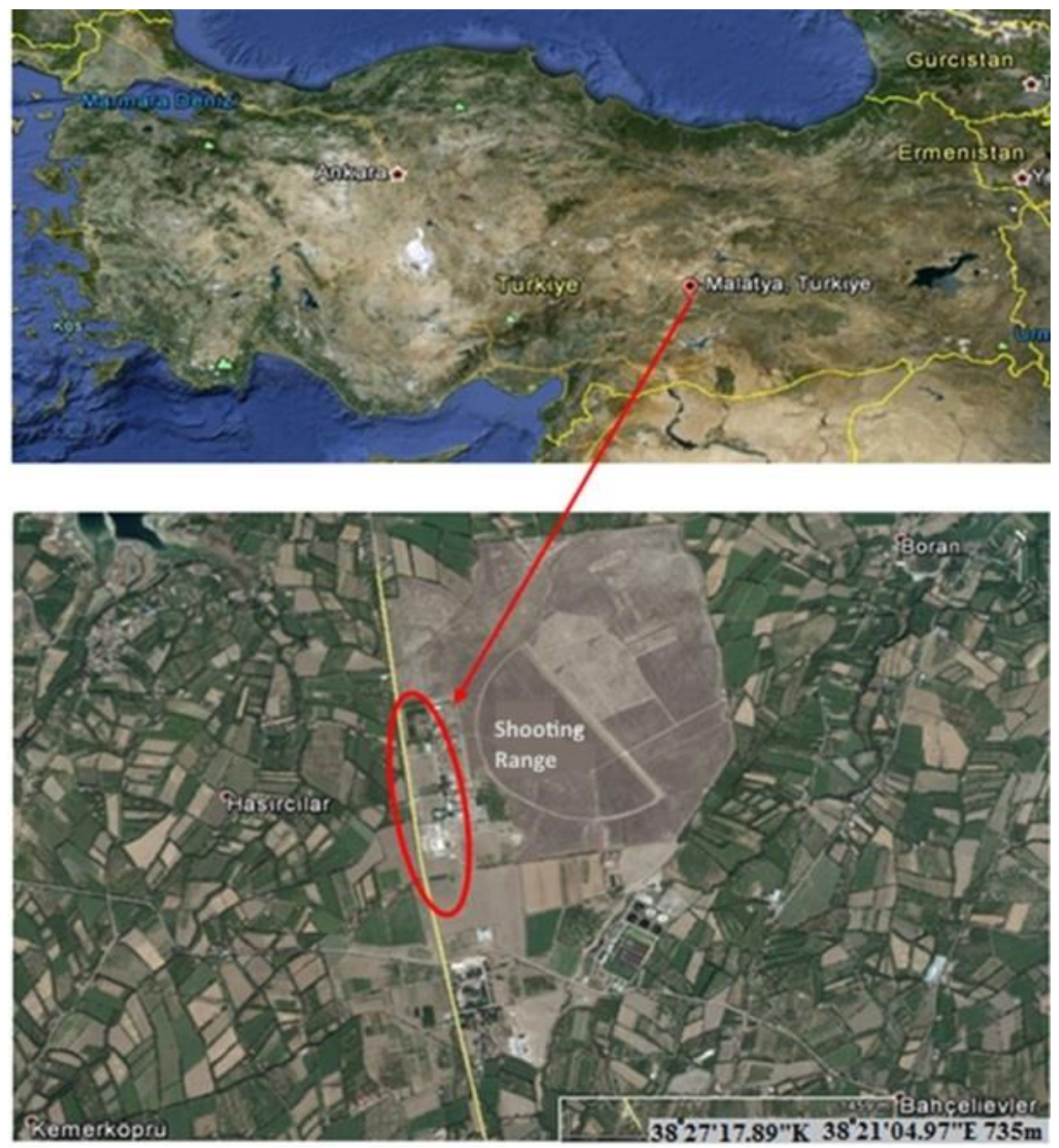

Figure 1. Location map of the study area [5]

\subsubsection{SPT}

The SPT is a simplistic and common test used in the calculations of the soil type, soil stiffness, resistance, liquefaction, and the bearing capacity for the foundation and estimated settlement. In the study, 15 boreholes were drilled and 7 SPTs were performed for each borehole to collect SPT samples. The drilling points of the study area are given in Figure 2. The standard penetration tests were carried out in the boreholes by ASTM D 1586 [6]. During the test, a hammer weighing $63.5 \mathrm{~kg}$ was dropped from $760 \mathrm{~mm}$ to achieve a free fall and the plunge of the SPT tube to $450 \mathrm{~mm}$. The number of blows for the penetration of the SPT tube to the last $300 \mathrm{~mm}$ was recorded as $\mathrm{N}_{30}$. Energy corrections were performed on the blow counts and the results were used in the comparisons. Among the samples collected during the SPT, the numbers of SPT blows (SPT-N) values obtained in the first $12 \mathrm{~m}$ were used. Each borehole had a diameter of $150 \mathrm{~mm}$ and the SPT-N values were measured for every $3 \mathrm{~m}$. Figure 3 shows the histogram plot and distribution of the SPT-N 60 values by depth. Sieve analysis according to ASTM D-422 and consistency limit tests according to ASTM D4318-17e1 were performed on disturbed samples taken from SPT [7, 8]. Table 1 shows the gravel and fine material contents and consistency values of the SPT samples and soil classification made according to USCS standard is given in Table 2 [9]. 


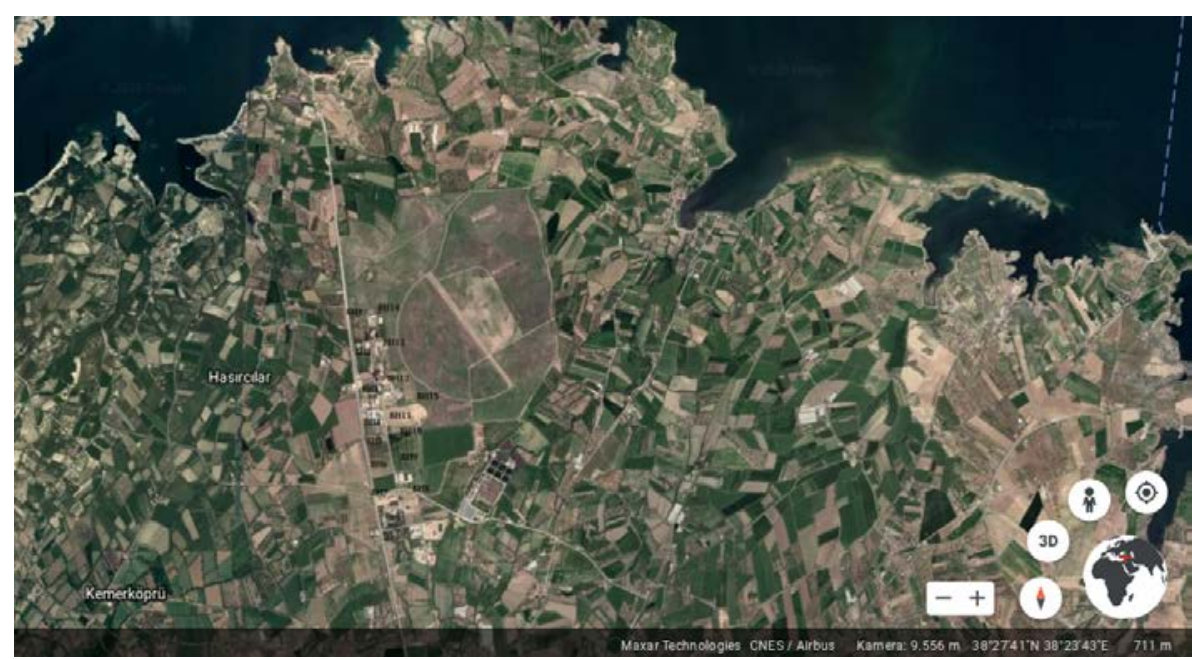

Figure 2. Study area drilling points

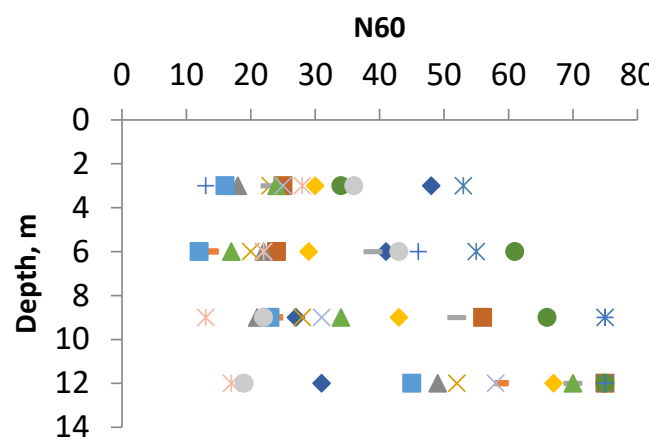

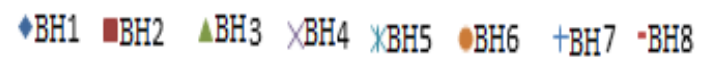

-BH9 $\triangle \mathrm{BH} 10 \mathrm{BH} 11 \mathrm{BH} 12 \times \mathrm{BH} 13 \times \mathrm{BH} 14 \quad \mathrm{BH} 15$
} a.

Figure 3. (a)SPT-N 60 values for depths (BH: Bore Hole) (b) The histogram plot of the SPT-N 60 values

\subsubsection{PMT}

The pressuremeter test was developed by Louis Menard and is frequently used in geotechnical projects to analyze soil properties. It is among the field tests used in the measurement of the characteristics of the lateral deformation of the test soil at a certain depth [10]. Compared with the SPT, the PMT is relatively costly and thus, is sometimes not preferred in small-scale or regular geotechnical applications [10]. Using the correlations established with the data obtained from the test, bearing capacity, internal friction angle, undrained shear stress, lateral stresses, elasticity module, and settlement can be calculated [11]. The PMT requires expertise and the SPT is a relatively more practical and easy test. Hence, correlations were also made between SPT results and the results from other field tests [12]. 
Table 1. Some Physical Properties of the SPT Samples

(BH: Bore Hole, NP: Non-plastic, LL: Liquid Limit, PI: Plasticity Index)

\begin{tabular}{|c|c|c|c|c|c|c|c|c|c|c|c|c|c|c|}
\hline 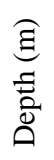 & 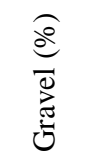 & 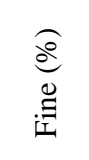 & G & $\bar{a}$ & 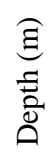 & 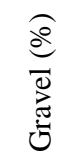 & 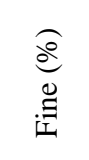 & $\exists$ & $\bar{a}$ & 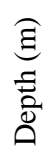 & $\frac{\stackrel{0}{0}}{\stackrel{0}{0}}$ & 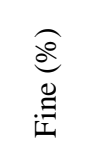 & 曰 & $\bar{a}$ \\
\hline \multicolumn{5}{|c|}{ BH: 1} & \multicolumn{5}{|c|}{ BH: 2} & \multicolumn{5}{|c|}{ BH: 3} \\
\hline 3 & 0 & 23.32 & 47.1 & 19.95 & 3 & 1.43 & 20.82 & 36.38 & 16.14 & 3 & 23.29 & 5.56 & 50.12 & 29.57 \\
\hline 6 & 0 & 15.75 & 50.03 & 21.23 & 6 & 8.26 & 5.82 & 31.61 & 14.05 & 6 & 25.91 & 9.64 & 39.22 & 18.83 \\
\hline 9 & 6.09 & 15.44 & 43.5 & 67.38 & 9 & 12.35 & 7.70 & 39.61 & 18.04 & 9 & 30.28 & 33.48 & 18.87 & 7.24 \\
\hline 12 & 13.83 & 21.28 & 35.25 & 14.70 & 12 & 29.63 & 7.56 & 30.75 & 9.15 & 12 & 47.49 & 4.06 & 22.24 & 7.30 \\
\hline \multicolumn{5}{|c|}{ BH: 4} & \multicolumn{5}{|c|}{ BH: 5} & \multicolumn{5}{|c|}{ BH: 6} \\
\hline 3 & 37.93 & 4.71 & NP & NP & 3 & 2.46 & 26.27 & 41.19 & 17.91 & 3 & 4.80 & 40.77 & 41.55 & 16.33 \\
\hline 6 & 10.02 & 14.56 & 23.42 & 8.56 & 6 & 6.26 & 16.26 & 26.63 & 6.62 & 6 & 10.23 & 25.89 & 45.73 & 19.21 \\
\hline 9 & 14.04 & 14.41 & 46.84 & 17.15 & 9 & 3.27 & 28.05 & NP & NP & 9 & 7.26 & 19.91 & 50.26 & 20.01 \\
\hline 12 & 23.98 & 6.40 & 69.95 & 34.43 & 12 & 0.28 & 39.85 & NP & NP & 12 & 8.67 & 32.62 & 56.97 & 21.30 \\
\hline \multicolumn{5}{|c|}{ BH: 7} & \multicolumn{5}{|c|}{ BH: 8} & \multicolumn{5}{|c|}{ BH: 9} \\
\hline 3 & 22.79 & 15.78 & 41.10 & 17.52 & 3 & 0.80 & 34.61 & 41.58 & 17.60 & 3 & 11.91 & 15.75 & 40.85 & 23.08 \\
\hline 6 & 26.44 & 17.27 & NP & NP & 6 & 15.16 & 31.27 & 37.75 & 14.01 & 6 & 15.63 & 17.31 & 28.71 & 13.35 \\
\hline 9 & 18.55 & 14.51 & 15.72 & 6.14 & 9 & 16.33 & 19.74 & 53.68 & 21.65 & 9 & 21.65 & 15.91 & 32.42 & 10.69 \\
\hline 12 & 18.93 & 8.69 & 38.67 & 16.79 & 12 & 4.38 & 24.01 & 70.96 & 29.69 & 12 & 28.71 & 9.90 & 42.05 & 16.16 \\
\hline \multicolumn{5}{|c|}{ BH: 10} & \multicolumn{5}{|c|}{ BH: 11} & \multicolumn{5}{|c|}{ BH: 12} \\
\hline 3 & 7.06 & 59.38 & 49.92 & 26.24 & 3 & 12.96 & 30.66 & 39.08 & 19.81 & 3 & 11.10 & 9.81 & 62.26 & 32.69 \\
\hline 6 & 7.06 & 60.84 & 47.60 & 23.52 & 6 & 14.03 & 35.42 & NP & NP & 6 & 4.36 & 31.39 & 79.53 & 47.15 \\
\hline 9 & 14.81 & 40.84 & 39.96 & 18.07 & 9 & 0 & 10.92 & NP & NP & 9 & 13.72 & 39.35 & 57.35 & 33.86 \\
\hline 12 & 14.91 & 23.49 & 52.75 & 24.23 & 12 & 9.91 & 25.51 & 74.73 & 36.90 & 12 & 21.23 & 33.14 & 35.92 & 16.54 \\
\hline \multicolumn{5}{|c|}{ BH: 13} & \multicolumn{5}{|c|}{ BH: 14} & \multicolumn{5}{|c|}{ BH: 15} \\
\hline 3 & 2.14 & 58.82 & 48.65 & 24.04 & 3 & 4.79 & 45.90 & 61.07 & 34.34 & 3 & 26.80 & 52.62 & 47.96 & 26.91 \\
\hline 6 & 0.07 & 62.42 & 50.41 & 25.95 & 6 & 4.82 & 38.13 & 66.97 & 37.95 & 6 & 0.78 & 44.71 & 46.57 & 26.09 \\
\hline 9 & 20.25 & 38.14 & 44.54 & 24.22 & 9 & 0.14 & 57.64 & 57.46 & 31.39 & 9 & 1.21 & 30.65 & NP & NP \\
\hline 12 & 38.80 & 12.14 & NP & NP & 12 & 0.21 & 73.97 & NP & NP & 12 & 0.55 & 28.13 & 33.85 & 13.22 \\
\hline
\end{tabular}


Table 2. Soil classification according to depth

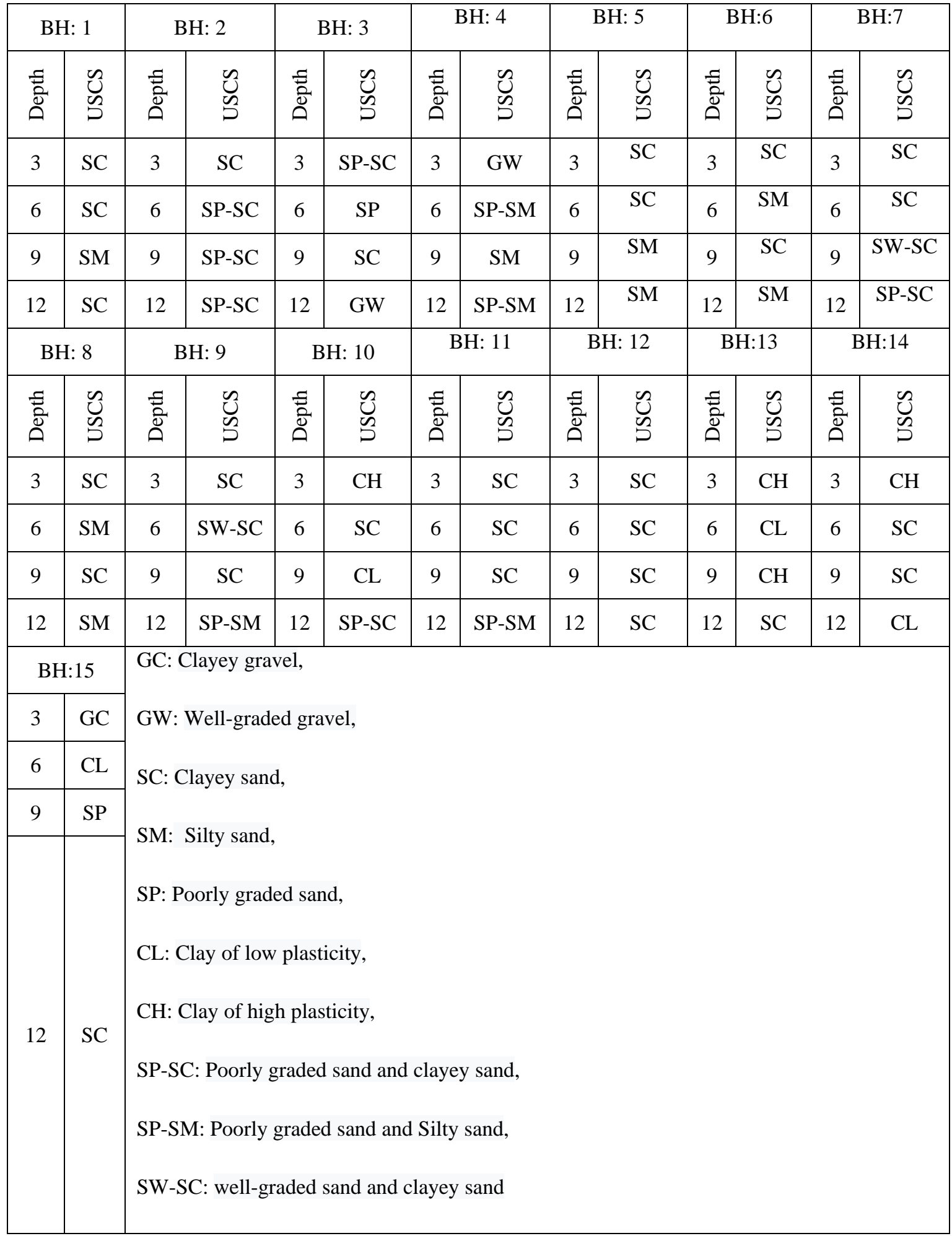

In their study published in 2016, Naseem et al. developed a correlation between SPT- $\mathrm{N}_{1,60}$ (Energy-corrected $\mathrm{N}$-value normalized to effective overburden stress of one atmosphere) and $\mathrm{P}_{\mathrm{L}}$ and $\mathrm{Em}_{\mathrm{m}}$. In the tests predominantly carried out in sandy soils, the SPT-N 1,60 blow counts were between 6 and 23. Eq. (1) and (2) give the correlations derived by the researchers. The $\mathrm{R}^{2}$ values were determined to be 0.857 and 0.8504 , respectively [11]. 
$P_{L}=15.214 . N_{1,60}+89.276$

$E_{m}=165.88 . N_{1,60}+1364.1$

In 1990, in their study investigating sandy and clay soils, Kulhawy and Mayne correlated SPT blow count with Em and carried out a PMT for the parameters used in foundation design [13].

Another correlation between the SPT and PMT was developed by Bozbey and Toğrol. In their study carried out in Istanbul in 2010, Bozbey and Togrol performed the SPT and PMT for sandy and clay soils and found a linear relationship between the SPT-N60, $\mathrm{E}_{\mathrm{m}}$, and $\mathrm{P}_{\mathrm{L}}$ values concerning the soil type $[10,14]$. The researchers determined that, in sandy soils, there was a correlation between the results of the SPT-N60 and PMT, which is as follows Eq. (3) [14]:

$E_{m}=1.33 .\left(N_{60}\right)^{0,77} \quad\left(\mathrm{r}^{2}=0.2\right)$

Again, in 2008, in their study on sandy, silty, and clay soils, Yağız et al. derived the following Eq. (4) [15]:

$E_{m}=388 N_{60}+4554 \quad\left(\mathrm{r}^{2}=0.91\right)$

In this study, 6 PMTs were carried out for each of the 15 boreholes with depths of $20 \mathrm{~m}$. The test was carried out following the ASTM D 4719. SPT and PMT tests were made by "Garanti Temel Teknik Sondaj- Elazı ğ" company [16]. The PMT results for the depths between $0 \mathrm{~m}$ and $12 \mathrm{~m}$ were used in the tests. To compare the data obtained from the SPT with the data obtained from the PMT, the mean 3m-deep SPT blow counts were used. Figure 4 shows the histograms and the PMT results for depth.

\subsubsection{MASW}

The MASW method is one of the most common methods used in determining the shallow seismic velocity of soil [17]. The $V_{s}$ value obtained with the MASW test is the fundamental parameter needed to identify the dynamic properties of soils [18]. It is conveniently used in the evaluation of certain parameters such as soil stiffness, liquefaction potential, soil density, soil classification, and foundation settlement [18].

The main goal of the MASW method is to obtain the dispersion of Rayleigh waves in which phase velocity is dependent on the frequency and convert it into S-wave velocity and layer depth using the inversion technique [17].

However, determining the $\mathrm{V}_{\mathrm{s}}$ wave velocity in all field applications is not always cost-friendly. Establishing a correlation between the $\mathrm{V}_{\mathrm{s}}$ and SPT blow counts reduces the cost of the field study. In 2014, Tumwesige et al. carried out a correlation study between $\mathrm{V}_{\mathrm{s}}$ and SPT-N blow counts. The researchers collected 273 data measurements for the $V_{s}$ and SPT-N at the same depth and showed that the relationship between the two parameters depended on the effective strain and ignoring this strain created a bias in the model [19]. In 2007, Anbazhagan et al. developed a correlation between the corrected SPT-N and $\mathrm{V}_{\mathrm{s}}$ values and the results of the 38 MASW tests carried out at a fairly close location to the drilling points [20]. 
Furthermore, in the USA, similar studies investigating the correlation between $\mathrm{V}_{\mathrm{s}}$ and $\mathrm{N}_{30}$ showed that corrected SPT-N values yielded better correlations compared with the uncorrected SPT-N values [21]. In Japan, a great number of researchers developed correlations between the SPT-N and $V_{s}$ values by taking the geological age and soil type into account. Among these studies, some used corrected SPT-N values, while others used uncorrected SPT-N values.

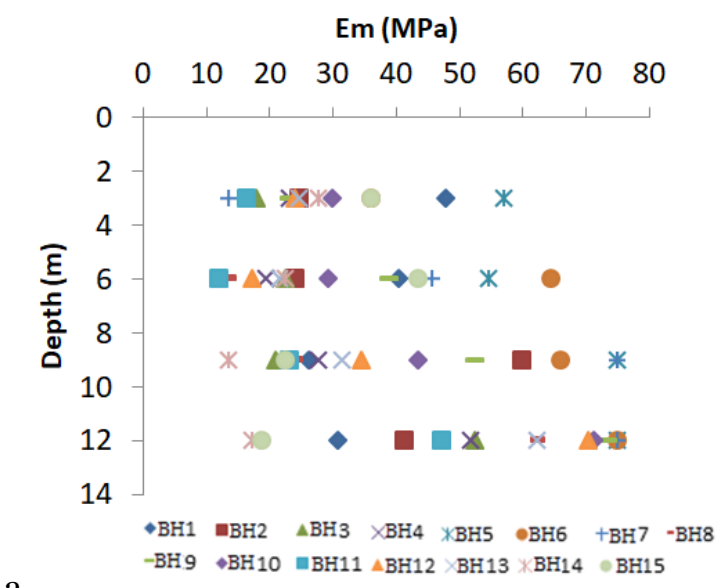

a.

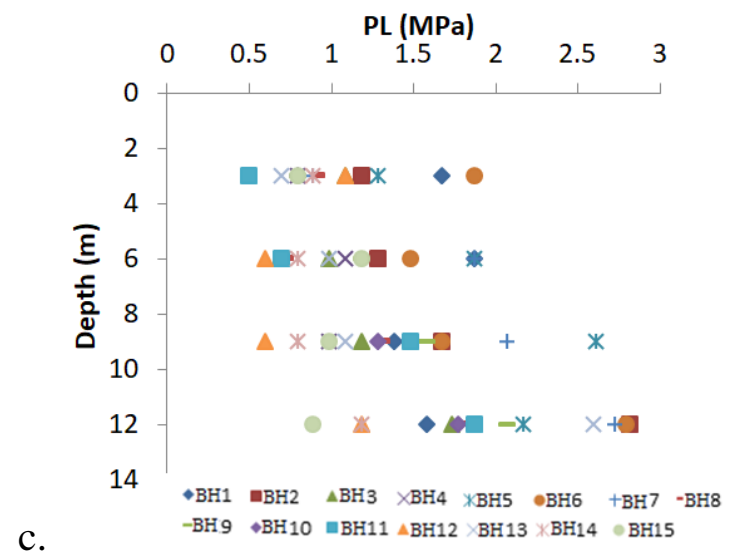

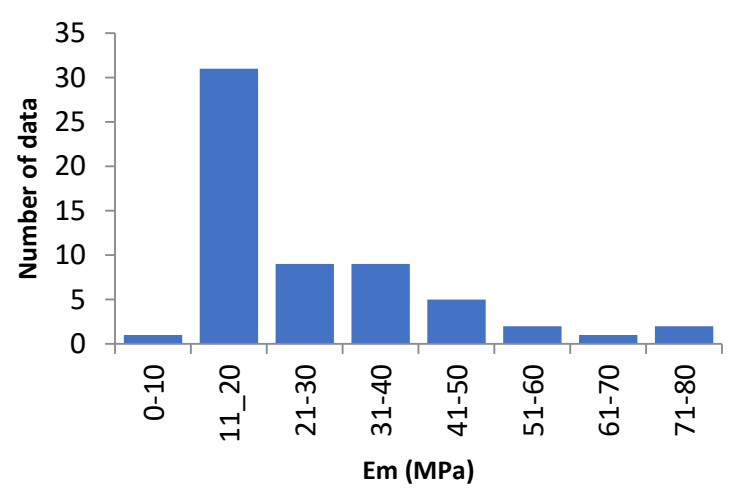

b.

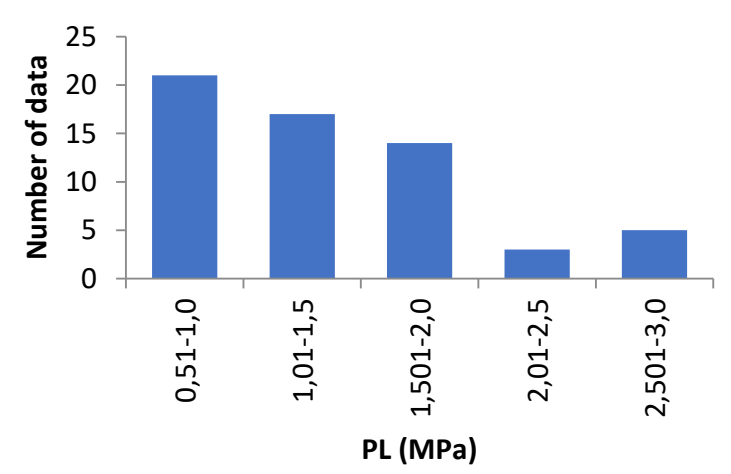

Figure 4. (a) $E_{m}$ values (b) Histogram of $E_{m}$ (c) $P_{L}$ values (d) Histogram of $P_{L}$

In this study, MASW measurements were performed at 32 locations and the measurements from the 15 closest locations to the drilling points were used for comparison purposes. Furthermore, the same as the case for the SPT and PMT values, the values obtained at the first $12 \mathrm{~m}$ were used for the comparisons. In the MASW test, a 12 channeled "Geometrics-Smartseis SE" model seismograph was used along with the use of an $8 \mathrm{~kg}$ sledgehammer and a $30 \mathrm{~cm} \times 30 \mathrm{~cm}$ plate as the seismic energy sources. Geophone spacing is taken as $2 \mathrm{~m}$, minimum offset $4 \mathrm{~m}$ and maximum offset 48m. MASW measurements were made by "Yerfiziği-Burhanettin TÜZÜN" company. Figure 5 shows the measurement results for MASW. 

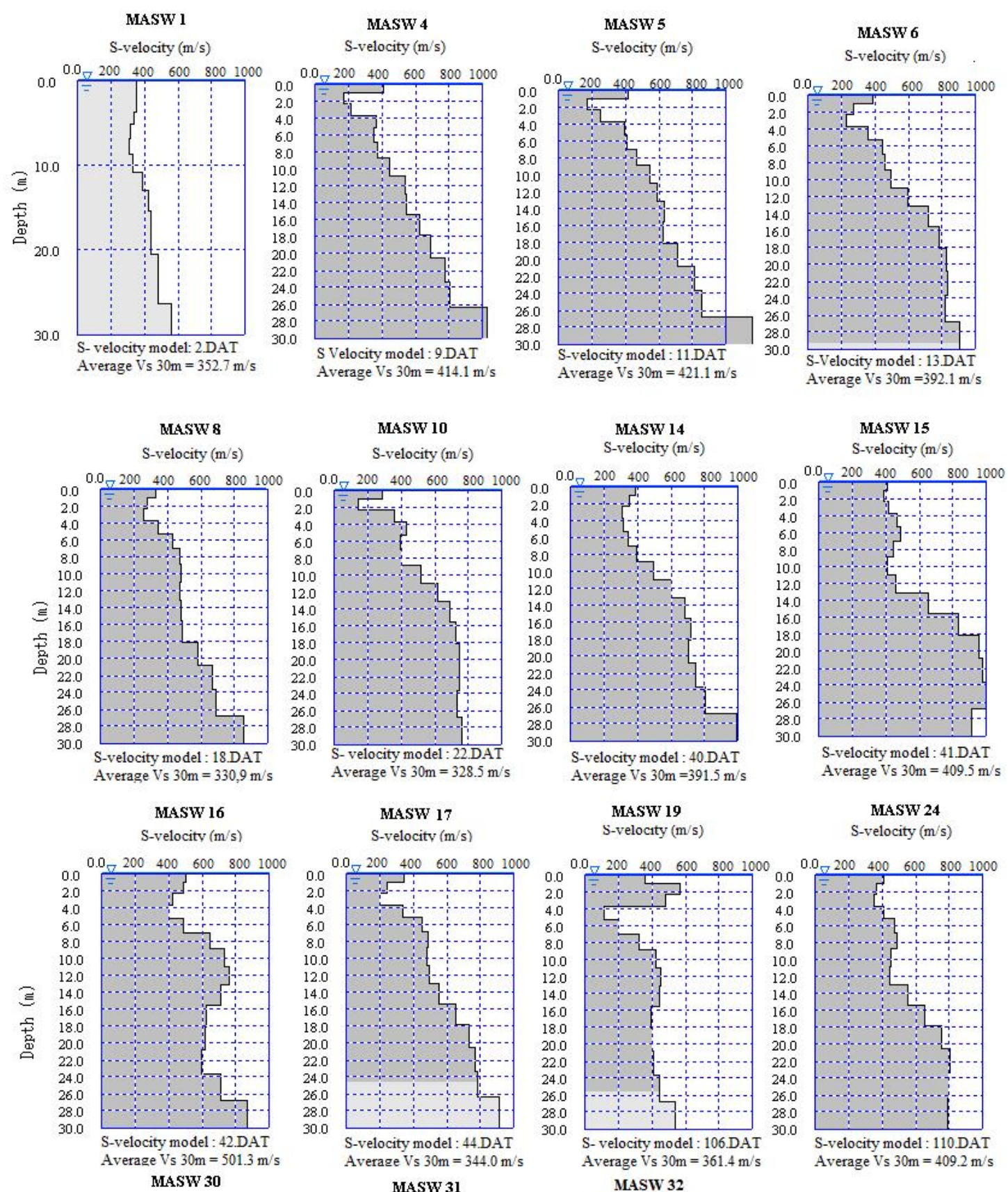

\section{MASW 19}

S-velocity $(\mathrm{m} / \mathrm{s})$

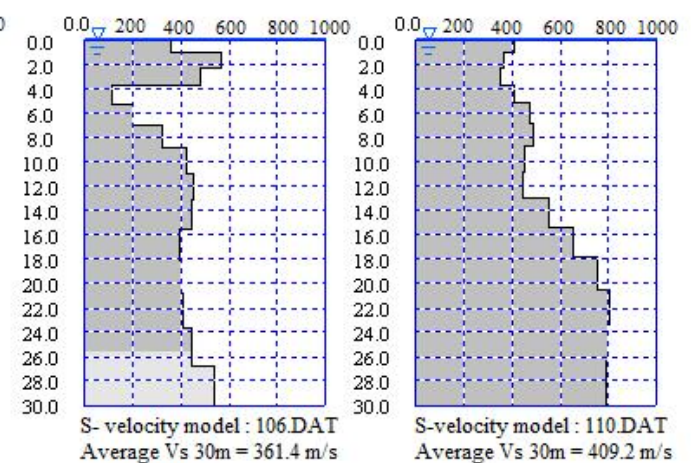

S-velocitv $(\mathrm{m} / \mathrm{s})$
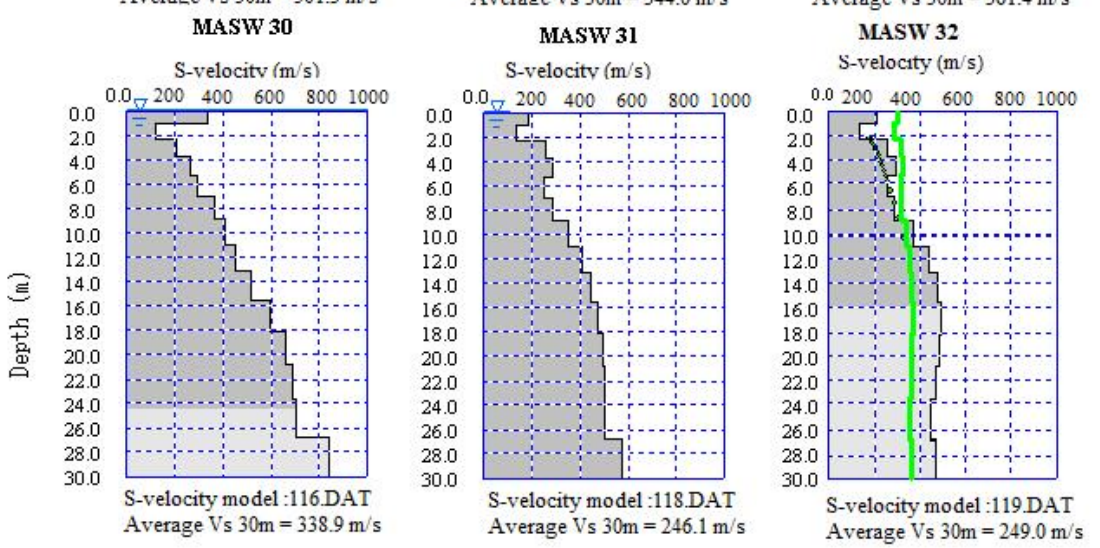

Figure 5. MASW measurement results 
Table 3 shows a summation of the correlations between SPT and $V_{s}$ found in the relevant literature. $\mathrm{N}_{30}$ was used in most of these correlations, while energy corrections (SPT-N60) were made in some of the studies [18].

Table 3. Summary of the Empirical Correlations Based on SPT-N vs $\mathrm{V}_{\mathrm{s}}$ [18]

\begin{tabular}{|c|c|c|c|}
\hline Researcher(s) & $\begin{array}{c}\mathrm{V}_{\mathrm{s}}= \\
(\mathrm{m} / \mathrm{s} \text {. for all } \\
\text { soils) }\end{array}$ & Researcher(s) & $\begin{array}{c}\mathrm{V}_{\mathrm{s}}= \\
(\mathrm{m} / \mathrm{s} \text {. for all } \\
\text { soils })\end{array}$ \\
\hline Kanai (1966) & $19 N^{0.6}$ & Imai and Tonouchi (1982) & $97 N^{0.314}$ \\
\hline Ohba and Toriumi (1970) & $84 N^{0.31}$ & Dikmen (2009) & $58 N^{0.39}$ \\
\hline Imai and Yosimura (1970) & $92 N^{0.329}$ & Iyisan (1996) & $51.5 N^{0.516}$ \\
\hline Fujiwara (1972) & $92.1 N^{0.337}$ & Kiku et al. (2001) & $68.3 N^{0.292}$ \\
\hline Ohsaki and Iwasaki (1973) & $82 N^{0.39}$ & Hasançebi and Ulusay (2007) & $90 N^{0.309}$ \\
\hline Imai and Yoshimura (1975) & $92 N^{0.329}$ & Uma et al. (2010) & $95.64 N^{0.301}$ \\
\hline Imai (1977) & $91 N^{0.337}$ & Athanasopoulos (1995) & $107.6 N^{0.36}$ \\
\hline Ohta and Goto (1978) & $85.35 N^{0.348}$ & $\begin{array}{c}\text { Hanumantharao and Ramana } \\
(2008)\end{array}$ & $82.6 N^{0.43}$ \\
\hline Seed and Idriss (1981) & $61 N^{0.50}$ & Jafari et al. (1997) & $22 N^{0.85}$ \\
\hline
\end{tabular}

\subsection{Correlations}

\subsubsection{The correlation between the PMT and SPT values}

After the energy corrections to the SPT-N values obtained with the field tests, the results were compared with the $E_{m}$ and $P_{L}$ values obtained from the PMT results. The $\mathrm{R}^{2}$ values for the correlations were 0.595 and 0.6847 , respectively (Figure 6).

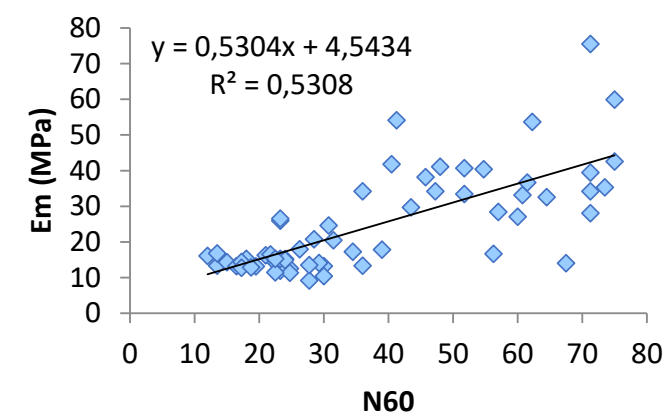

a.

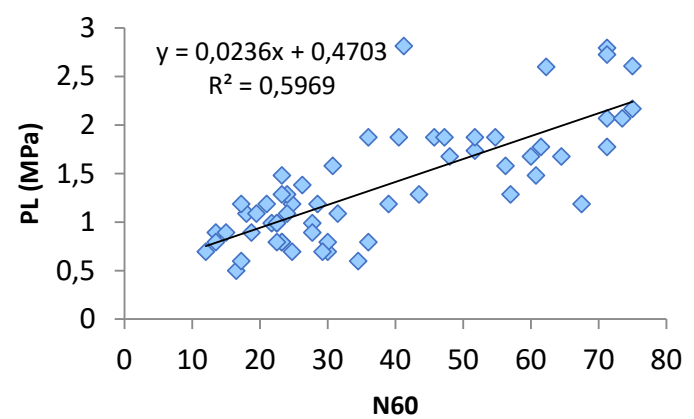

b.

Figure 6. Correlation between (a) SPT- $\mathrm{N}_{60}-\mathrm{Em}$, (b) SPT-N $\mathrm{N}_{60}-\mathrm{P}_{\mathrm{L}}$

\subsubsection{The correlation between the SPT and MASW values}

The SPT-N60 values were used in the comparisons with the MASW results and the $\mathrm{R}^{2}$ value for the derived correlations was 0.5719 (Figure 7). 


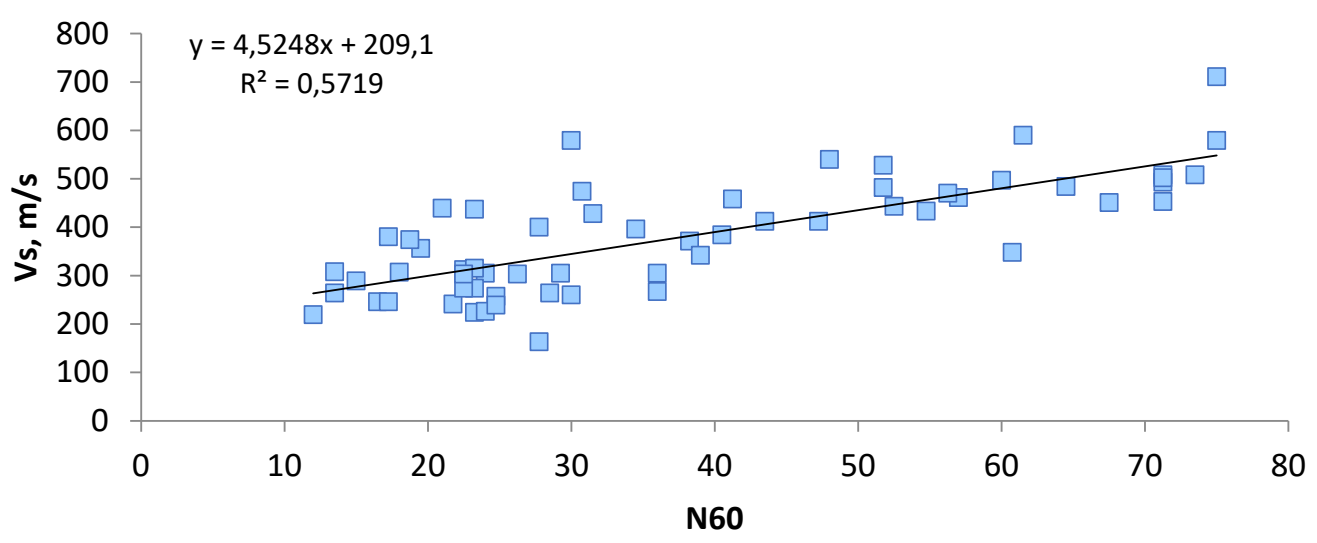

Figure 7. Correlation between SPT- $\mathrm{N}_{60}-\mathrm{V}_{\mathrm{s}}$ values

The results obtained from the tests were compared with the results found in the relevant literature and are given in Figure 8. In the study area, silty sand and clayey sand units are observed intensively. These units are concentrated in areas where the relationship is reduced relationship of the parts is also increased gravel unit. As the ratio of gravel increases, the soil becomes heterogeneous and the relationship becomes weak. When Figure 8 is examined; The measured values were found to be heavily compatible with Ohsaki and Iwasaki (1973) and Iyisan (1996). It is believed that the stiffening and gravel ratio in the remaining spots are effective.
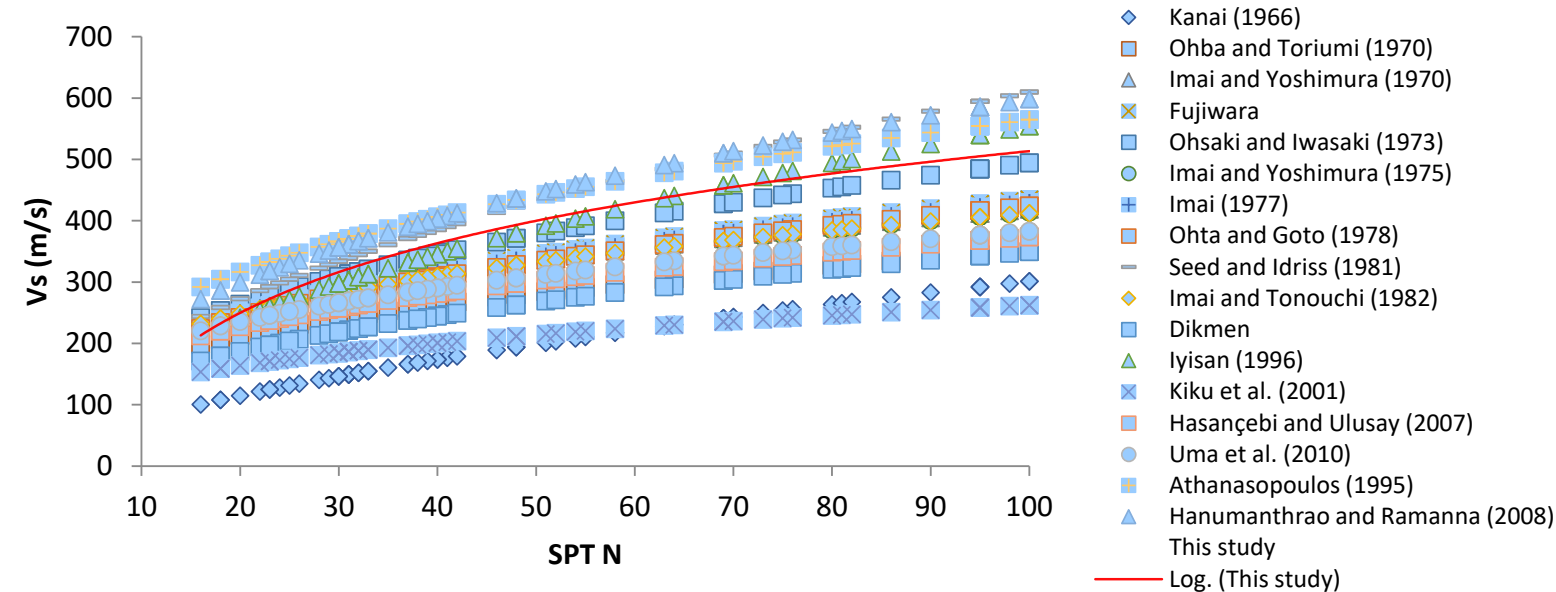

Figure 8. The comparison of the MASW and SPT results with the data found in the literature

\subsubsection{The correlation between the PMT and MASW values}

Figure 9 shows the correlations between the $E_{m}$ and $P_{L}$ values obtained with the PMT and the $\mathrm{V}_{\mathrm{s}}$ values obtained with the MASW. The $\mathrm{R}^{2}$ values were 0.3906 and 0.4524 , respectively. 


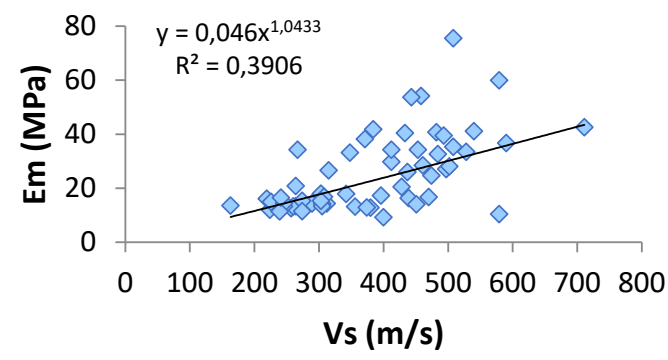

a.

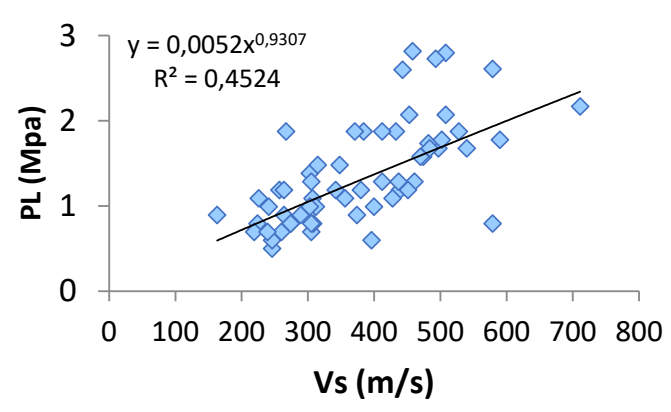

b.

Figure 9. Correlation between (a) $\mathrm{V}_{\mathrm{s}}-\mathrm{E}_{\mathrm{m}}$, (b) $\mathrm{V}_{\mathrm{s}^{-}} \mathrm{P}_{\mathrm{L}}$

\section{RESULTS AND DISCUSSION}

The study investigates the relationship between the results obtained from the SPT, PMT, and MASW tests using simple regression analysis. A correlation study was carried out between the results obtained from the SPT and PMT tests performed for the 15 boreholes at certain intervals and the results obtained from the MASW test performed for the closest locations to the boreholes.

a. The study area is made up of the flood deposits from the Euphrates River. In light of the geophysical studies carried out across the field, the thickness of the unit was determined to be $70 \mathrm{~m}$. The unit has a complex structure that densely contains a silty sandy unit and in which large gravel blocks and clay bands are frequently encountered at different depths. According to the MASW test results, across the field, the north and northeast regions densely contained a silty clay unit, while, in the west and northwest regions, the silty clay units are accompanied by gravel (Figure 10).

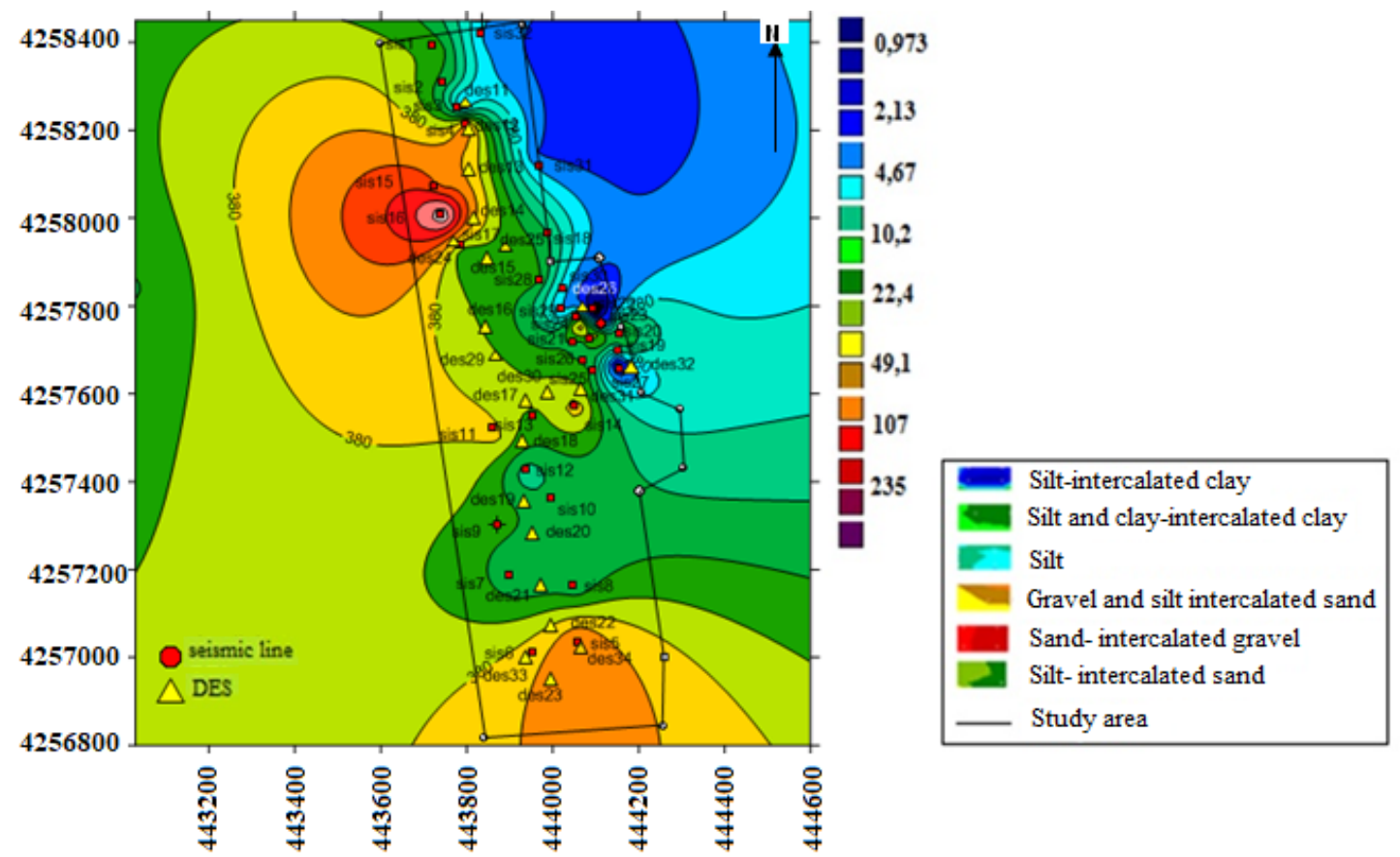

Figure 10. The lithological distribution of the study area according to the MASW test results 
b. The correlations obtained in the study are given below. According to the table, the strongest correlation was determined between the $\mathrm{P}_{\mathrm{L}}$ and SPT-N60 values, while the weakest correlation was determined between the $E_{m}$ and $V_{s}$ values (Table 4). as shown in Table 4, the highest relationship is between PMT and SPT. The fact that these tests were conducted in-situ in the same borehole may have increased the relationship. As seen in Table 2 and Figure 10, the study area is a very heterogeneous region. it is believed that $\mathrm{R}^{2}$ values are therefore low. Other studies in the literature have mostly been done in homogeneous areas. These studies were mostly conducted in areas where sand or silt was dense. It is believed that $\mathrm{R}^{2}$ values in the literature are therefore high.

Table 4. Correlation between the tests

\begin{tabular}{|c|c|c|c|c|c|}
\hline Relation & $E_{m}-V_{s}$ & $P_{L}-V_{s}$ & $S P T-N_{60}-V_{s}$ & $E_{m}-S P T-N_{60}$ & $P_{L}-S P T-N_{60}$ \\
\hline $\mathrm{R}^{2}$ & 0.3906 & 0.4524 & 0.5719 & 0.5950 & 0.6847 \\
\hline
\end{tabular}

c. $\mathrm{N}_{30}, \mathrm{E}_{\mathrm{m}}, \mathrm{P}_{\mathrm{L}}$, and $\mathrm{V}_{\mathrm{s}}$ values increased depending on the depths. An increase in soil stiffness depending on depth can be cited as the reason for this.

d. The comparison of the $\mathrm{V}_{\mathrm{s}}$ and SPT-N 60 measured in the study area with the curves obtained in previous studies showed that they remained approximately in the same region (Figure 8). In the study area, silty sand and clayey sand units are observed intensively. These units are concentrated in areas where the relationship is reduced relationship of the parts is also increased gravel unit. As seen in Figure 8, this is thought to be the reason why the test results remain in the same area as previous studies.

\section{CONCLUSIONS}

This study emphasizes that homogeneity and tightness are effective in correlation studies. Studies in the literature were mostly conducted in homogeneous areas. Therefore, $\mathrm{R}^{2}$ values are high. But because the heterogeneity of alluvial deposits is higher, the relationships established in these soils have also been weak. in studies conducted in heterogeneous areas, it is recommended that the relationship between these tests be evaluated in detail by other researchers.

\section{Acknowledgments}

We would like to thank the Inonu University Scientific Research Project Department, who financially supported this study with Project No. 2013/61. 


\section{REFERENCES}

[1] Anbazhagan, P., Kumar, A. and Sitharam, T.G. (2013). Seismic site classification and correlation between standard penetration test $N$ value and shear wave velocity for Lucknow City in Indo-Gangetic Basin. Pure and Applied Geophysics 170: 299-318.

[2] Samui, P. and Sitharam, T. (2010). Correlation between SPT, CPT and MASW. Int J Geotechnical Eng 4(2):279-288.

[3] Kirar, B, Maheshwari, B.K. and Muley, P. (2016). Correlation between shear wave velocity (Vs) and SPT resistance $(N)$ for Roorkee Region. Int J Geosynthetics and Ground Eng 2( 9):1-11.

[4] Onal, M. (1995). Miocene stratigraphy and lignite potential of the northern part of the Malatya graben basin Eastern Anatolia- Turkey. International Earth Science Colloquium on the Aegean Region Proceedings, İzmir 11:607-621.

[5]https://earth.google.com/web/@38.45696612,38.37107435,731.29476775a,8724.63210368d,35y,1.84813536 $\mathrm{h}, 0 \mathrm{t}, 0 \mathrm{r}$

[6] ASTM D1586 / D1586M-18, Standard Test Method for Standard Penetration Test (SPT) and Split-Barrel Sampling of Soils, ASTM International, West Conshohocken, PA, 2018, www.astm.org

[7] ASTM D 422-63, 2003. Standard Test Method for Particle-Size Analysis of Soils, In Annual Book of ASTM Standards, Volume 04.08, Philadelphia, PA, pp. 93-99.

[8] ASTM D4318-17e1. Standard Test Methods for Liquid Limit, Plastic Limit, and Plasticity Index of Soils; ASTM International: West Conshohocken, PA, USA, 2017.

[9] ASTM D2487-17e1. Standard Practice for Classification of Soils for Engineering Purposes (Unified Soil Classification System); ASTM International: West Conshohocken, PA, USA, 2017.

[10] Cheshomi, A. and Ghodrati, M. (2014). Estimating Mernard pressuremeter modules and limit pressure from SPT in silty sand and silty clay soils. A case study in Mashhad, Iran. Geomechanics and Geoengineering 10(3):194-202.

[11] Naseem, A. and Jamil, S.M. (2016). Development of correlation between standard penetration test and pressuremeter test for clayey sand and sandy soil. Soil and Foundation Eng 53(2): 98-102.

[12] Anwar, M.B. (2016). Correlation between PMT and SPT results for calcareous soil. Housing and Building National Research Center 14(1): 50-55.

[13] Kulhawy, F.H. and Mayne, P.W. (1990). Manual on estimating soil properties for foundation design. Electric Power Research Institution Rep-EL-6800 Final report, August, Project 1493-6.

[14] Bozbey, I. and Togrol, E. (2010). Correlation of standard penetration test and pressuremeter data a case study from Estunbol, Turkey. Bulletin of Eng Geology and the Env 69: 505-515.

[15] Yagiz, S., Akyol, E. and Sen, G..(2008). Relationship between the standard penetration test and the pressuremeter test on sandy silty clays: a case study from Denizli. Bulletin of Eng Geology and the Env 67(3): 405410.

[16] ASTM D4719, Standard test method for pre-bored Pressuremeter Testing in soils ASTM International, West Conshohocken, 2000.

[17] Park, C.B., Miller, R.D. and Xia, J. (1999). Multichannel analysis of surface waves. Presented at the 66th Annual Meeting, Society of Exploration Geophysicists 64(3): 800-808.

[18] Akin MK, Kramer SL and Topal T (2011) Empirical correlations of shear wave velocity (Vs) and penetration resistance (SPT-N) for different soils in an earthquake-prone area (Erbaa-Turkey). Eng Geology 119: 1-17. 
[19] Tumwesige, R., Gidudu, A., Bagampadde, U. and Ryan, C. (2014). An investigation of the relationship between standard penetration test and shear wave velocity for unsaturated soils (A case study of the earthquake prone area of The Albertıne Graben). Second Conference on Earthquake Engineering and Seismology Istanbul, Turkey pp 25-29.

[20] Sitharam, T.G. and Anbazhagan, P. (2007). Seismic hazard analysis for the Bangalore Region. Natural Hazards 40: 261-278.

[21] Mhaske, S.Y. and Choudhury, D. (2011). Geospatial contour mapping of shear wave velocity for Mumbai City, Natural Hazards 59: 317-327. 